\title{
Editors' Report
}

\section{Editors' Report, 2012}

\author{
Yoon K. Loke, ${ }^{1}$ Adam F. Cohen, ${ }^{2}$ Albert Ferro, ${ }^{3}$ Lionel D. Lewis, ${ }^{4}$ James M. Ritter ${ }^{3} \&$ \\ Andrew A. Somogyi ${ }^{5}$ \\ ${ }^{1}$ Norwich Medical School, University of East Anglia, Norwich, UK, ${ }^{2}$ Centre for Human Drug Research, Leiden, the Netherlands, ${ }^{3}$ Department of Clinical \\ Pharmacology, School of Medicine (Cardiovascular Division) King's College London, London, UK, ${ }^{4}$ Section of Clinical Pharmacology, Department of \\ Medicine, The Geisel School of Medicine at Dartmouth \& Dartmouth-Hitchcock Medical Center, Lebanon, NH, USA and ${ }^{5}$ Discipline of Pharmacology, \\ School of Medical Sciences, University of Adelaide, Adelaide, SA, Australia
}

During 2012 (January-December issues) BJCP published: 10 Editors' views, 1 Editors' report, 1 Editors' pick, 1 Editorial commentary, 1 Viewpoint, 44 Reviews, 1 Systematic review, 121 Main papers, 10 Short reports, 1 Case report, 6 Commentaries, 8 Book reviews, 1 New Drug Mechanisms, 15 Letters to the Editors, 1 Obituary and 2 Proceedings/ Abstracts. There were two themed issues 'Agenda for Clinical Pharmacology' and 'Prescribing'.

A key change in 2012 was the decision to remove the category of Short reports which in the past have attracted relatively few citations (some previously accepted papers in this category were published). Important papers do not have to be long to be accepted, but authors should select another category for them. The Editorial Board continued its focus on high quality invited reviews and this is illustrated in the statistics of the following paragraph.

We received 646 submissions (15\% higher compared with 2011), of which $398(+11 \%)$ were original papers. Of the original articles, $17 \%$ have been accepted, with the remainder rejected, pending a decision or awaiting a revision. We have seen a more than $30 \%$ rise in submissions of reviews and meta-analyses, with 109 to date, as compared with 81 in 2011.

Overall submissions for the period 31 October 2011 to 1 November 2012 came from 52 countries (49 countries in 2011 and 54 in 2010): United Kingdom (157,21.0\% of total), USA (99, 13.3\%), China (61, 8.2\%), the Netherlands (51, $6.9 \%)$, France (38, 5.1\%), Australia (35, 4.7\%), Germany (32, $4.3 \%)$, India $(29,3.9 \%)$, Italy $(26,3.5 \%)$, Japan $(25,3.4 \%)$, Switzerland (20, 2.7\%), Spain (18, 2.4\%), Denmark (13, $1.7 \%)$, Sweden $(13,1.7 \%)$, Korea (12, 1.6\%), Canada (10, $1.3 \%$ ) and 36 other countries ( $<10$ submissions each).

Papers were submitted and handled electronically via the ScholarOne website.

Median times were as follows:

- from submission to first decision 24 days as compared with 40 days in 2011
- from submission to final acceptance 80 days as compared with 115 days in 2011

- from receipt at Wiley-Blackwell to accepted Article publication 9 days as compared with 8 days in 2011

- from receipt at Wiley-Blackwell to print publication 153 days as compared with 135 days in 2011

These results show remarkably positive improvements, especially in the categories 'from submission to first decision', which has decreased by 16 days (20\%) and 'from submission to final acceptance', which has decreased by 35 days. This reflects the outstanding commitment by Editors, Executive Editors and Referees in a time of rising submissions. However, the rise in number of submissions, coupled with the faster flow through to Acceptance has the unintended effect of creating a longer wait for print publication. Since very few of our subscribers pay for a print subscription, the BPS (the owner of BJCP as well as of our sister Journal BJP) has decided to discontinue print publication and from January 2013, both these journals are 'online only'. This opens up a number of opportunities which we shall describe more fully in an upcoming editorial.

The impact factor is 2.96 , a decline of $9 \% . \mathrm{BJCP}$ is ranked 81 st out of 261 journals in Pharmacology and Pharmacy, a slip of seven positions. It is unclear if this is noise or signals a trend but we believe that our continued focus on high quality original articles and reviews is, in either case, the appropriate response.

\section{Changes in the editorial boards}

\section{Editors}

Sarah Ross (Aberdeen), one of our executive editors, is taking on specific responsibility as Educational Affairs Editor from January 2013, reflecting the BPS policy to promote educational needs of members and of clinical pharmacologists and prescribers world-wide. 


\section{Executive editorial board}

Alan Boddy, Nuala Helsby, Isla Mackenzie, Carmel McEniery and Sarah Ross joined the executive editorial board. We would like to express our appreciation for the dedication and hard work from those who have served on the executive editorial board: Henry Chrystyn, Alyn Morice, John Posner, Raymond McAllister, Jan Schellens and Oliver von Richter.

\section{International editors}

Gilberto De Nucci, Dieter Deforce, Nithya Gogtay, Gary Maartens, Pertti Neuvonen, Kyoichi Ohashi, Eiji Uchida and Nicholas White joined the International Editorial Board. We are grateful to Maria de Moraes, Stephen Evans and Pauli Ylitalo who have concluded their terms.

The Editors thank all Board Members, both Executive Editors and International Editors, for their massive contri- butions over the past year: time has never been so much at a premium and the editors and the Society are mindful of and extremely grateful for the generosity of our editorial team in this regard. Without them and their commitment it is no exaggeration to say that there would be no BJCP.

\section{Logistical matters}

The management board continues to have monthly teleconferences which have helped to streamline the journal processes and to deal with appeals in a fair and structured manner. We thank all the publishing staff at WileyBlackwell including Stephen Montgomery (Managing Editor), Victoria Renigan (Editorial Assistant), Amanda Hunter (Production Editor) and Phil Wright (Marketing) for their unwavering and enthusiastic support, led expertly and overseen with calm efficiency by our publisher, Elizabeth Whelan. 